\title{
Sydney epilepsy incidence study to measure illness consequences: the SESIMIC observational epilepsy study protocol
}

\author{
Maree L Hackett ${ }^{1 *}$, Nicholas S Glozier ${ }^{2}$, Alexandra L Martiniuk ${ }^{3}$, Stephen $\operatorname{Jan}^{4}$, Craig S Anderson ${ }^{1}$
}

\begin{abstract}
Background: Epilepsy affects an estimated 50 million people and accounts for approximately 1\% of days lost to ill health globally, making it one of the most common, serious neurological disorders. While there are abundant global data on epilepsy incidence, prevalence and treatment, there is a paucity of Australian incidence data. There is also a general lack of information on the psychosocial impact and socioeconomic consequences of a new diagnosis of epilepsy on an individual, their family, household, and community which are often specific to the health and social system of each country.

Methods/Design: The Sydney Epilepsy Incidence Study to Measure IIIness Consequences (SEISMIC) is an Australian population-based epilepsy incidence and outcome study that will recruit every newly diagnosed case of epilepsy in the Sydney South West Area Health Service to an epilepsy register. Multiple and overlapping sources of notification will be used to identify all new cases of epilepsy over a 24 month period in the Eastern Zone of the Sydney South West Area Health Service (SSWAHS) and follow up will occur over 12 months. SEISMIC will use the International League Against Epilepsy (ILAE) definitions and classifications for epidemiologic studies of epilepsy. The study will examine outcomes including mood, quality of life, employment, education performance, driving status, marital and social problems, medication use, health care usage, costs and stigma.

Discussion: This study is designed to examine how clinical, psychological factors, socioeconomic circumstances, and healthcare delivery influence the experience of epilepsy for individuals and families allowing better targeting of specific services and informing policy makers and practitioners. In addition, the study will provide the basis for a longitudinal population-based cohort study and potentially inform qualitative sub-studies and randomised controlled trials of intervention strategies. The study has been registered on the Australia New Zealand Clinical Trial Registration database with ANZCTRN12609000059268.
\end{abstract}

\section{Background}

Currently there is very limited evidence about the burden of epilepsy in the Australian population. The best available estimates based on a cross sectional survey in Tasmania and a study conducted 30 years ago suggest that it is prevalent in between 6 and 7.5 per 1000 people $[1,2]$. This equates to approximately 150,000 people in Australia presently living with this condition making it one of the 50 leading causes of disease burden and injury in the country [3]. Globally about 50 million

\footnotetext{
* Correspondence: mhackett@george.org.au

${ }^{1}$ Neurological and Mental Health Division, The George Institute for Global Health, The University of Sydney, Sydney, Australia

Full list of author information is available at the end of the article
}

people are affected by epilepsy, which accounts for about $1 \%$ of days lost to ill health globally [4]. The average incidence across developed countries has been estimated at 43.4/100,000 [5] which would suggest that over 8,800 Australians develop the condition every year. Despite the potential magnitude of the burden of epilepsy, population-based Australian data on the natural history of epilepsy are limited, and strategies to reduce the considerable psychosocial and economic impact of epilepsy are lacking, or poorly understood.

Epilepsy is a chronic neurological disorder with the fundamental characteristic of recurrent, intermittent seizures unprovoked by any acute medical condition or transient brain disorder. A diagnosis of epilepsy is made

\section{C) Biomed Central}


in those more than 44 weeks post conception, following a second unprovoked seizure occurring at least 24 hours after the first. However "epilepsy" incidence studies have used varying definitions, often including people with single seizures.

Age-specific incidence of epilepsy is bimodal: it is high in those aged over 60 years and highest in children and adolescents, with a slight predominance in males $[5,6]$. However, it is commonly thought that incidence rates are underestimated in the elderly due to incomplete case ascertainment in studies. Three recent studies have demonstrated a higher incidence in lower income groups in the United Kingdom, New York and Iceland [7-9] and incidence appears to be higher in developing countries [5].

Epilepsy is associated with increased mortality [10], including increased risk of sudden unexpected death (SUDEP) [11], and morbidity: this may be physical (e.g. fractures, scalding, bruising) occurring directly as result of seizures, cognitive (e.g. cognitive delay, speech or language difficulties, learning disabilities), behavioural (e.g. aggression) $[12,13]$, or psychosocial (e.g. depression, anxiety, stigma).

\section{Seizure Treatment}

The goal of initial treatment is to achieve seizure control by preventing seizure recurrence and maintaining optimal physical, cognitive, behavioural and emotional function. Approximately $60-70 \%$ of people with new onset epilepsy become, and remain, seizure free with appropriate medication [14]. In many of these cases drug treatment can be withdrawn after seizure remission, although the risk of relapse remains high [15]. However, about one third of incident cases have recurrent seizures [6]. The longer term influence of antiepileptic drugs is unknown [16]. Despite the magnitude of the problem, and the effectiveness and relatively low cost of treatment, many patients may not receive effective treatment through lack of adherence to medication, reduced availability of diagnosis and drugs e.g. living in a rural area or inability of the individual or health system to pay for treatment, such as in a low income country [17]. Further, there may be delays in seeking help due to ignorance, fear, stigma [18], illiteracy and cultural attitudes towards treatment (e.g. attributing epilepsy to possession).

\section{The psychosocial impact of epilepsy}

The social sequelae of epilepsy are far reaching and potentially include the loss of a driving licence, lack of access to or change in employment or education circumstances, marital and social problems, taking regular medication and dealing with the responses of others to the diagnosis including perceiving and experiencing stigma and discrimination [18]. Reduced social participation, physical inactivity, and higher healthcare usage are also more common in people with epilepsy [19]. As a group, people with epilepsy have poorer psychosocial functioning than those without epilepsy [20].

Psychological comorbidities such as anxiety, depression [21-23] and sleep disturbance [24] are common in people with epilepsy, and increase the risk of suicide [25]. Lifetime prevalence estimates of major depressive disorder are as high as $17.4 \%$ (95\% CI 10-24.9), mood disorders $24.4 \%$ (16.0-32.8) and anxiety disorders $22.8 \%$ (14.8-30.9) in people with epilepsy, who were more than twice as likely than people without epilepsy to report such disorders [26]. Problems in the areas of attention, cognition and socialisation are also apparent in children with epilepsy [27].

Psychosocial sequelae have a greater impact on healthrelated quality of life (HRQoL) than short-term seizure control $[28,29]$. Veterans with epilepsy with a comorbid psychiatric diagnosis (depression, anxiety, substance abuse or post traumatic stress disorder) had HRQoL scores $24 \%$ lower on all eight domains the SF-36 than veterans with epilepsy alone [30]. People with epilepsy and depression are more likely to report having seizures than those without depression [31] and seizure activity explains much of the variation in psychosocial functioning [22]. Whilst more frequent seizures are associated with impaired HRQoL, and even infrequent seizures (less than one per year) impair HRQoL in older adults, stigma is found to be the strongest predictor of reduced HRQoL [20,29,32]. Despite psychosocial impairment accounting for a large proportion of the negative outcomes experienced by people with epilepsy, there has been little investigation into the natural history of these psychosocial problems [33]. While the data are limited, there may be some association between marital (unmar$\mathrm{ried} / \mathrm{separated} /$ divorced) [31,34] and employment (unemployed) [31,34] status, increasing number of medical problems [31], lower education, income [35], activity, social support and increased stigma [34] and the risk of depression.

The development of interventions in this area lags behind pathophysiological and pharmacological research. It has been postulated that stigma may be moderated by individual resilience-based factors such as self esteem and social support which, if confirmed, offer promising areas for intervention [36]. However, there is also little information on the nature of social support required by patients, or the impact of epilepsy on carers, the family or the household.

\section{The economic impact of epilepsy}

There are limited data on the economic impact of epilepsy on the individual, their family or the community. 
Despite calls from the ILAE in 1997 for cost-utility analyses to measure psychosocial and other subjective patient-reported outcomes [37], economic data collected to date are limited to socioeconomic disparities in incidence, epilepsy-related health service costs and gaps in delivery of appropriate treatment $[8,17,38]$. It is possible that socioeconomic disparities in incidence (increased incidence with more socioeconomic deprivation) may be a result of confounding [8]. The highest expenditure for the household of individuals with epilepsy appears to occur in the first year after diagnosis which reflects higher use of specialist services over that period [38]. However, when considering costs to a country, a large proportion of the burden comes from indirect costs such as unemployment and early mortality [39]. There is an urgent need for reliable information on the direct and indirect costs of the condition and for a better understanding of the factors that are associated with adverse economic outcomes for patients, their families and the community.

\section{Australian data}

A high quality longitudinal, prospectively recruited population-based sample of Australians with incident epilepsy is lacking. The limited Australian epidemiological epilepsy data are predominantly from cross-sectional surveys of people currently accessing health care for epilepsy, in addition to some early studies of Sydney general practitioners' knowledge of, management of and attitudes towards epilepsy [40]. An early Sydney study using ' 3 or more seizures verified by a doctor' to define epilepsy found a prevalence of 7.5 per 1,000, with remission $(30 \%$ off medication) and medication usage (70\%) as the primary endpoints [1]. This prevalence estimate was adjusted to 1 in 50 in a subsequent analysis [41]. A retrospective study on SUDEP in Victoria [42] which led to a prospective case-cohort coronial deaths study of SUDEP found that young people with epilepsy are more likely to die in their sleep than their counterparts [43]. More recently a survey of Tasmanian residents on the Australian National prescription database who had been prescribed an antiepileptic drug for epilepsy or seizures was conducted. This study showed that one quarter of participants reported very high levels of psychological distress from anxiety and mood disorders, with this group also having higher usage of healthcare services [44].

\section{Scientific rationale for a study of newly diagnosed epilepsy in Australia}

The gold standard study design to determine the true impact of epilepsy is a large-scale, longitudinal, prospective, population-based incidence and outcome study which allows observation of the natural history of all aspects of epilepsy across the age and severity spectrum.
Such a design will enable identification of potentially modifiable determinants of outcome including clinical, psychological, social and economic factors that reduce vulnerability or enhance resilience to the psychosocial and socioeconomic consequences of epilepsy in Australia.

\section{Methods/Design}

\section{Design and Overview}

The Sydney Epilepsy Incidence Study to Measure Illness Consequences (SEISMIC) is a prospective, populationbased epilepsy incidence and outcome study with study registration number ACTRN12609000059268. The primary aim of SEISMIC is to identify modifiable factors that enhance resilience and reduce vulnerability to the socioeconomic impact of epilepsy in an Australian population. We hypothesise that a) psychological factors (depressive and anxiety symptom burden, and coping) are associated with socioeconomic outcomes (school performance, work absence, family impact and economic hardship), and b) social and economic deprivation, and service access factors are associated with variation in disability and clinical outcomes from epilepsy.

\section{Study Population \\ Inclusion criteria}

The population to be surveyed and monitored includes people more than 44 weeks post conception (i.e. excluding neonates) fulfilling all of the following criteria:

- New diagnosis of epilepsy, and

- Residing within the SSWAHS Eastern Zone geographical boundaries for the past month

- They or their "responsible person" (relative/friend) are able to provide written informed consent. Participants with a severe language disorder or cognitive impairment (as indicated by their clinician) are eligible to take part in the study providing their relative/friend is able to provide written informed consent and complete the assessments on the participant's behalf), and

- Consent is given to contact the GP if necessary in the case of a severe psychiatric disorder warranting treatment.

\section{Exclusion criteria}

- Seizures due to acute cerebral insult or reversible metabolic courses.

\section{Population Base}

The population to be surveyed and monitored includes those who are usually resident in the Eastern Zone of the SSWAHS http://www.sswahs.nsw.gov.au. In 2006 the estimated resident population of the SSWAHS was 510,000 people, and comprised 7 local government areas. Children under the age of 15 constitute $16 \%$ of the population; people aged 65 years and over make up 
about $12 \%$ and indigenous people comprise $1 \%$ of the population. This area is characterized by its multicultural character, with $39 \%$ speaking a language other than English at home. Furthermore this population has some of the poorest communities in the State, characterized by a large number of recent migrants, significantly higher unemployment and a high proportion of families dependent on welfare. Overall $40 \%$ of the area's population live in rented accommodation. The following hospitals or health-care centres are either in the Eastern Zone of the SSWAHS or treat people with epilepsy who reside within the catchment area: Bankstown Hospital, Brain and Mind Research Institute, Concord Repatriation Hospital, Prince of Wales Hospital, Royal Prince Alfred Hospital, St Vincent's Hospital, Sydney Children's Hospital at Randwick, Westmead including Westmead Children's Hospital. The rooms of private epileptologists, neurologists and paediatricians will also operate as recruiting sites.

\section{Case ascertainment and consent}

The lead clinician at each public or private site will act as the "principal investigator" (PI). The PI will be required to consent potentially eligible cases, or their parent (for potential cases aged 18 years or under), or guardian (for potential cases unable to consent themselves) of people with new diagnoses of epilepsy into the study. Each PI will maintain a log of every potentially eligible patient who is approached to participate in the study. The logs contain the initials and date of birth of the eligible patients, the date they were screened for participation in the study, whether or not consent to participate was obtained and if not, the reason for their non-participation. Participants consent to: 1) the abstraction of information about their epilepsy from medical records; 2) interviews at baseline (as soon as possible after diagnosis), four months and one year (primary endpoint), and; 3) for the participant's general practitioner (GP) to be contacted by research staff if necessary. All PIs or their research staff are contacted weekly to track screening and recruitment.

To ensure identification of all people with a new diagnosis of epilepsy in the SSWAHS who are not seen in a public hospital, regular liaison and collaboration with General Practitioners (GP), paediatricians and private neurologists in the area is essential. Various methods will be used to initiate and maintain a high level of awareness of the study in the community, including 6 monthly contacts to enquire about potentially eligible participants, and provision of pamphlets, magnets, posters and training for clinicians and allied health professionals.

In addition PIs may consent participants with their first unprovoked seizure, who do not currently meet the criteria for a diagnosis of epilepsy, into the SEISMIC First Seizure substudy. These people will be asked to allow 6 monthly contact from the research team to ascertain if there has been any clinical changes that would warrant their subsequent inclusion as a case of new onset epilepsy over the course of the study's recruitment.

\section{Assessments and data collection}

The detailed schedule for data collection is shown in Table 1. Researchers will travel to the recruitment site of consented participants and abstract the following data from consented participants' medical notes: initials, date of birth, sex, contact information, source of notification (hospital, private site, general practitioner etc) and clinical information. Data are entered onto electronic case report forms (eCRFs) and uploaded to a secure centralised database.

\section{Baseline interview}

This will be conducted through a structured face to face interview by a trained researcher at a place of the participant's or their family's convenience. Participants complete a clinical and an age-specific psychosocial assessment.

The clinical assessment for all participants, or their parent, proxy, carer or guardian includes a clinical and modified-Austin interview [45]. This questionnaire collects information on epilepsy onset and prodromal characteristics, seizure type classification and syndromal classification, complete description of seizure: type, duration, and frequency; other ictal phenomena such as falls; and duration of post-ictal recovery, any symptom side effects if prescribed antiepileptic drugs, details of neurological investigation results (e.g.: EEG, MRI etc) and medical factors potentially associated with morbidity including comorbidity, family history and potential aetiological factors e.g. head injury, birth asphyxia.

Following completion of the clinical assessment, participants or their proxy complete either the adult/ guardian or the parent/carer of a child assessment as appropriate.

The adult psychosocial interview with participants who are 18 years of age or older consists of detailed demographic, psychosocial and socioeconomic questions including: duration of residence in Australia, physical and social living situation, medical history, general wellbeing, education and employment, household financial circumstances, transport, social support, mood, stigma and sleep. At the end of the interview, all participants are given the opportunity to provide any other information about their experience or circumstances that has not been covered during the interview.

The parent or carer psychosocial interview for participants who are between 0 and 18 years of age consists of 
Table 1 Schedule of assessments in the SESIMIC study

\begin{tabular}{|c|c|c|c|}
\hline Participant Assessment $^{a}$ & Baseline $^{b}$ & 4 month & 12 month \\
\hline Initials & $x$ & & \\
\hline Date of birth & $x$ & & \\
\hline Sex & $x$ & & \\
\hline Inclusion criteria & $x$ & & \\
\hline Contact information & $x$ & & \\
\hline \multicolumn{4}{|l|}{ Interview Characteristics } \\
\hline Method of assessment & $x$ & $x$ & $x$ \\
\hline Participant or proxy & $x$ & $x$ & $x$ \\
\hline Alive at scheduled time of assessment & $x$ & $x$ & $x$ \\
\hline Telephone Interview for Cognitive Status (TICS) [63] & $x$ & $x$ & $x$ \\
\hline \multicolumn{4}{|l|}{ Seizure characteristics [45] } \\
\hline Consciousness & $x$ & & \\
\hline Onset & $x$ & & \\
\hline Frequency & $x$ & $x$ & $x$ \\
\hline Phenomena & $x$ & $x$ & $x$ \\
\hline Precipitants & $x$ & & \\
\hline Family history & $x$ & & \\
\hline Epilepsy-related medical history & $x$ & & \\
\hline New medical problems & & $x$ & $x$ \\
\hline Modified Cumulative Illness Rating Scale [66] & $x$ & $x$ & $x$ \\
\hline Birth History & $x$ & & \\
\hline Medication & $x$ & $x$ & $x$ \\
\hline Investigations (EEG, CT, MRI etc) & $x$ & $x$ & $x$ \\
\hline Accidents/falls/injuries & & $x$ & $x$ \\
\hline Access to services & & $x$ & $x$ \\
\hline Final diagnosis & & $x$ & \\
\hline Developmental milestones & & $x^{c}$ & $x^{c}$ \\
\hline Cognitive assessment (optional) & & $x$ & $x$ \\
\hline
\end{tabular}

\section{Demographic characteristics}

\begin{tabular}{lll}
\hline Born in Australia & $X$ & \\
\hline Years lived in Australia & $X$ & \\
\hline Language other than English spoken at home & $X$ & $X$ \\
\hline Marital status & $X$ & $X$ \\
\hline Number of financially dependent children & $X$ & $X$ \\
\hline Social/financial living status & $X$ & $X$ \\
\hline
\end{tabular}

\section{Medical History}

Psychotropic medications

Brief Illness Perceptions Questionnaire [48]

WHO Disability Assessment Schedule [67]

Strengths and Difficulties Questionnaire [50]

Alcohol consumption: Audit Alcohol Use Disorders Identification Test (AUDIT-C) [51]

\section{Education and Employment}

Highest qualification

Current student

Absences from education

Lifetime occupation

Current occupation

$\begin{array}{lll}x & x & x \\ x & x & x \\ x^{a} & x^{a} & x^{a} \\ x^{c} & x^{c} & x^{c} \\ x^{a} & x^{a} & x^{a}\end{array}$

Current occupation 
Table 1 Schedule of assessments in the SESIMIC study (Continued)

\begin{tabular}{|c|c|c|c|}
\hline Job content questionnaire [53] & $x^{a}$ & $x^{a}$ & $x^{a}$ \\
\hline \multicolumn{4}{|l|}{ Financial Situation } \\
\hline Household benefits & $x$ & $x$ & $x$ \\
\hline Main source of income & $x$ & $x$ & $x$ \\
\hline Insurance & $x$ & $x$ & $x$ \\
\hline Economic hardship & $x$ & $x$ & $x$ \\
\hline Income & $x$ & $x$ & $x$ \\
\hline \multicolumn{4}{|l|}{ Transport } \\
\hline Vehicles driven and frequency & $x^{a}$ & $x^{a}$ & $x^{a}$ \\
\hline Transport to work/education & $x^{a}$ & $x^{a}$ & $x^{a}$ \\
\hline Drive for work & $x^{a}$ & $x^{a}$ & $x^{a}$ \\
\hline \multicolumn{4}{|l|}{ Childcare } \\
\hline Location & $x^{c}$ & $X^{c}$ & \\
\hline Duration & $x^{c}$ & $x^{c}$ & \\
\hline Absence from childcare & $x^{c}$ & $X^{c}$ & \\
\hline \multicolumn{4}{|l|}{ Support } \\
\hline Confiding relationship & $x$ & $x$ & $x$ \\
\hline Family adaptation, partnership, growth affection, resolve questionnaire [55] & $x$ & $x$ & $x$ \\
\hline Inventory of Family Protective Factors [56] & $x$ & $x$ & $x$ \\
\hline Social media use & $x$ & $x$ & $x$ \\
\hline \multicolumn{4}{|l|}{ Mood } \\
\hline Hospital Anxiety and Depression Scale [57] & $x^{a}$ & $X^{a}$ & $X^{a}$ \\
\hline General Health Questionnaire & $x^{c}$ & $X^{c}$ & $X^{c}$ \\
\hline \multicolumn{4}{|l|}{ Stigma } \\
\hline Modified HIV Stigma Scale [59] & $x$ & $x$ & $x$ \\
\hline Disclosure of epilepsy diagnosis & $x$ & $x$ & $x$ \\
\hline \multicolumn{4}{|l|}{ Sleep } \\
\hline Pittsburgh Sleep Quality Index [60] & $x$ & $x$ & $x$ \\
\hline \multicolumn{4}{|l|}{ Health related quality of life } \\
\hline EuroQol [47] & $x^{a}$ & $x^{a}$ & $x^{a}$ \\
\hline Quality of Life in Epilepsy for Adolescents [61] & $x^{b}$ & $x^{b}$ & $x^{b}$ \\
\hline Longitudinal Study of Australian Children [62] & $x^{d}$ & $x^{d}$ & $x^{d}$ \\
\hline
\end{tabular}

the same information as above with the addition of questions about childcare. Adolescents (between 11 and 18 years of age) and children (between 5 and 10 years of age) also complete age-specific quality of life questionnaires. At the end of the interview, all participants are given the opportunity to provide any other information about their experience or circumstances that has not been covered during the interview.

\section{4 month interview}

Participants complete a clinical and an age-specific psychosocial assessment covering the four month period since their diagnosis. The clinical assessment for all participants consists of a review of seizure frequency since last interview, clinical investigations, medications, general health, developmental milestones and an optional cognitive assessment if deemed necessary by the interviewer. The adult, parent or carer interviews are as outlined previously.

\section{2 month interview}

Participants complete a clinical and an age-specific psychosocial assessment covering the previous 8 month period. The clinical assessment for all participants is as outlined at the four month assessment with a reassessment of the diagnosis of epilepsy or epilepsy syndrome. 
The adult, parent or carer interviews are as outlined previously.

\section{Specific questionnaires used include}

The EuroQol (EQ-5D) [46,47] is a measure of quality of life that provides a simple descriptive profile and a single value for health status graded on a scale from -0.59 to 1.00. Lower scores indicate poorer quality of life. A score of 0 represents no quality of life and scores less than 0 represent states perceived by the respondent to be worse than death.

The Brief Illness Perception Questionnaire (BIPQ) [48] is a valid and reliable measure of patients' cognitive and emotional representations of their illness across a variety of illness groups. The BIPQ assesses consequences, timeline, personal control, treatment control, identity, coherence, concern, emotional response, and causes of illness. Items are rated using a 0 (not at all) to 10 (severely affects my life) response scale.

Psychosocial disability is assessed using the 12-item World Health Organisation Disability (WHO) Assessment Schedule (WHO-DAS II) [49]. The 12-item WHO-DAS II assesses the magnitude of disability over the previous 30 days using a five point scale from none to extreme/cannot do. Total scores range from 0-100 with higher scores indicating greater disability.

The Strengths and Difficulties Questionnaire (SDQ) [50] is a brief behavioural screening questionnaire for parents of 4 to 16 year olds which screens for child psychiatric disorders. In addition to assessing common emotional and behavioural difficulties, it also asks if the parent/carer/ proxy thinks that the child has problems in these areas and if there is associated distress and social impairment. The SDQ consists of 5 domains with 5 items per domain with responses ranging from 0 (not true) to 2 (certainly true) with higher scores indicating more problems.

The Alcohol Use Disorders Identification Test (AUDIT-C) [51] uses three questions to collect information on 'at-risk' alcohol consumption. Individual question scores range from zero to four. At risk alcohol consumption is indicated by a total score of five or more for males or four or more for females.

Information on paid and unpaid work is collected using modified versions of questions 34-51 of the Australian Bureau of Statistics 2006 Census [52] relating to jobs and work. Participants are asked to indicate whether there has been any change in employment circumstances since their diagnosis. Specific barriers to return to work are determined using the short form of the Job Content Questionnaire (JCQ) [53]. This widely used measure assesses job demands, control over work and support received.

Household economic hardship is determined by a series of questions about failure to make household payments and whether there was help provided by any organisation or individual to meet these payments. An advantage of this measure is that it is sensitive to the possibility that individuals prioritise certain payments (e.g. default on power bills to pay rent). The basis for these questions is the US Census Survey of Income and Program Participation [54].

The Family Adaptation, Partnership, Growth, Affection, Resolve (APGAR) [55] questionnaire is a valid and reliable 5-item instrument for assessing perceptions of adequacy of social support among adults and children. Items are rated using a three point scale from 'hardly ever' to 'almost always'. Total scores range from 0 (perceives inadequate support) to 10 (perceives adequate social support).

The Inventory of Family Protective Factors (IFPF) [56] is a 16-item scale which assesses stressful events the family may have experienced and how they were handled. Item scores range from 1 (not at all like my family) to 5 (almost always like my family). Total scores range from 16 to 80 with high scores indicating a perceived high degree of protection provided by the family.

The Hospital Anxiety and Depression Scale (HADS) [57] is used to collect information on depression and anxiety. The HADS is a self-report instrument designed for use with medically ill patients. Scores of 8 (possible range $0-21$ ) or more on the depression or anxiety subscales are classified as 'depressed' or 'anxious', respectively. Consent has been obtained to convey scores of 8 or more directly to participants' nominated GP who will be permitted to arrange treatment or formal referral for abnormal mood symptoms according to their clinical judgement.

The General Health Questionnaire (GHQ-12) [58] assesses psychiatric morbidity including general level of happiness, experience of depressive and anxiety symptoms, and sleep disturbance over the last four weeks. The four-item responses range from 0 (not at all) to 1 (much more than usual) with bimodal item scoring. Total scores range from 0 to 12 with scores of 4 or more considered experiencing high psychiatric morbidity.

The HIV Stigma Scale [59] has been modified for use in people with epilepsy. This scale assesses 1) Personalized stigma: consequences of other people knowing they have epilepsy 2) Disclosure concerns 3) Negative self image: not as good as others, shame, guilt and 4) Public attitudes: what people think about epilepsy. The four-item responses range from 1 (strongly disagree) to 4 (strongly agree) with total scores ranging from 10 to 40 with lower scores indicating less experienced or perceived stigma.

The first seven items of the Pittsburgh Sleep Quality Index (PSQI) [60] are used to measure sleep quality over the previous month. Item responses range from 0 (not during the past month) to 3 (three or more times per week) with higher scores indicating more sleep disturbance. 
The Quality of Life in Epilepsy for Adolescents (QOLIE-AD-48) [61] scale assesses the affects of epilepsy and antiepileptic medications, and daily activities for adolescents aged between 11 and 18 years of age. Items are rated on a 5 point scale from 1 (poor/much worse) to 5 (much better) with higher scores indicating better health-related quality of life.

Selected sections of questions from the Longitudinal Study of Australian Children (LSAC) [62] are used to assess child care, education (use, level, absence and performance) and mood.

The Telephone Interview for Cognitive Status (TICSM) [63] has been validated for assessment of cognitive function for research purposes. The 13-item TICS-M test includes orientation, recent and delayed memory, attention and comprehension assessment with a maximum score of 39. As the TIICS-M can be administered via the telephone it can be used in people with visual difficulties or poor hand-eye co-ordination.

\section{Diagnostic committee review}

In all cases, information gathered from the treating clinician's notes through the diagnostic proforma and the baseline clinical interview with the participant will be reviewed by the Diagnostic Committee for a final decision as to the diagnosis. The diagnostic committee comprises a panel of Sydney epilepsy specialists. Epilepsy will be defined according to the ILAE guidelines [64]. A clinical diagnosis will rely upon two criteria:

(a) Clear evidence of recurrent epileptic seizures, with evidence that these are unprovoked by any acute medical condition or transient brain disorder; and

(b) Documentation of diagnosis by someone with appropriate specialized training in the recognition of epilepsy. This allows for the inclusion of those who have an enduring predisposition to generate epileptic seizures yet have only had one seizure.

Each participant will be allocated to one of the following groups:

Definite epilepsy, with primary documentation that meets criteria: a) clear evidence of two or more unprovoked epileptic seizures that have occurred over interval(s) exceeding 24 hours, or b) confirmed diagnosis of epilepsy by a health care provider with appropriate specialised training in the recognition and treatment of epilepsy.

Probable epilepsy, with other sources of information indicating the likelihood that criteria (a) or (b) are met. Documentation of a diagnosis of epilepsy by a trained non-specialist health care provider without specific documentation of definite criteria above.

Possible epilepsy: requires further information from the baseline interview to confirm this and identify the seizure type classification.

Other seizure type: provoked seizure (acute symptomatic) e.g. post acute head injury, non-epileptic non-organic seizures (panic, psychogenic etc), non-epileptic organic seizures (syncope etc)

$$
\text { Not epilepsy }
$$

\section{Statistical considerations \\ Sample size assumption}

In the most recent census [52] there were 510,000 people usually resident in the Eastern zone of the SSWAHS. SEISMIC can expect to recruit 254 people with epilepsy per year for a total of 508 over the two year recruitment period. With an estimated 5\% refusal, we can expect 484 people to be recruited.

Adults In a Tasmanian cross sectional survey approximately $30 \%$ of adults with epilepsy reported psychological morbidity, which is associated with increased disability (e.g. taking more sickness or disability days). In an American study having chronic epilepsy and depression was associated taking 4 more disability days per month than those without [65]. If we hypothesise that participants with psychiatric co-morbidity experience 5 disability days vs. 3 disability days per month for those without psychiatric co-morbidity and the standard deviation (SD) of these is 4 then we are looking for an effect size of 0.5 . With $90 \%$ power, an alpha of 0.05 would require a sample of 191 (64 with psychiatric comorbidity, 127 without) to detect this difference in disability days per month (total sample 143 at $80 \%$ power). With the incidence assumptions from above, two years of recruitment would be adequate to detect this in working age adults and evaluate employment consequences of epilepsy as well as providing some leeway for multivariate modelling and interactions.

Children In the SSWAHS 39\% of families speak a language other than English at home. If we hypothesis that this is associated with a greater economic household impact through e.g. increased likelihood of not making a basic household payment, then the sample size recruited in two years above is sufficient to detect a relative risk of 1.5 for this poorer socioeconomic outcome.

\section{Statistical Analysis}

The incidence of epilepsy will be reported as definite cases of epilepsy over the population of the study area. Incidence will also be reported by age and syndromic groups. Data analysis will use multivariable one-level (SAS Proc Genmod) as well as mixed model approaches, which take variations within cluster (patients) and between clusters (e.g. hospitals) into account (SAS Proc Mixed). Mixed model approaches will be of use when cluster and individual level data are used to explain a possible outcome, for example, process of care by hospital along with individual level data on language spoken at home as risk factors for adherence to medication. 
Multivariable regression will be used to examine the contributions of protective and risk factors on several clinical, psychosocial and economic outcomes. Hypothesised and known risk factors from the literature will be used in the initial regression models, together with factors with a p-value of less than 0.2 in univariate analyses which will be considered as potential confounders. Relative risks and their corresponding 95\% confidence intervals will be presented for risk factors as they relate to the outcomes of interest.

Since the length of follow-up for participants will differ depending on the date of diagnosis and hence enrolment into the incident cohort, length of time in the study (and therefore at risk) will be taken into account in regression models. Potential effect modifiers will be examined by inserting interaction terms into the multivariable models.

Survival analyses will be used to investigate the time trajectory of risk and protective factors for various poor outcomes. Kaplan-Meier survival curves will be produced and then the adjusted survival will be examined using Cox proportional hazards models in order to take into account multiple exposure variables.

\section{Ethical approval}

Full ethical approval was provided by the Human Research Ethics Committee/08/RPAH/258 (lead committee) of the SSWAHS for protocol No X08-0152 on $10^{\text {th }}$ July 2008 and from local institutional research governance offices for each clinical centre or PI. Written informed consent is obtained for every participant or their parent, carer, guardian or proxy.

\section{Discussion}

Epilepsy is a costly, stigmatized and neglected condition. With the rapidly changing demographic and ethnic makeup of the Australian population, a populationbased study of this condition is timely. Through SEISMIC the rates of different epilepsy syndromes, overall and by sex and age group, will be determined for Australia. A feature of this study is its multidisciplinary approach in assessing the impact of epilepsy on individuals, their families and to the community.

SEISMIC will contribute information to promote a healthy life by providing information that will help address the psychosocial and economic impact associated with epilepsy which will ultimately help people live fulfilling and productive lives. The current paucity of prospectively collected population-based Australian data on people with epilepsy hinders the development of programs to reduce this burden. For the first time, data on psychosocial well-being, economic hardship, stigma, and service use following epilepsy will be collected.

\section{The SEISMIC collaborative group*}

\section{Advisory Committee}

Craig Anderson, Sam Berkovic (C), Wendyl D'Souza, John Dunne, Michelle Kiley, Cecilie Lander, Sue Ronaldson

\section{Grant Holders}

Craig Anderson (PI), Andrew Bleasel, Nick Glozier, Maree Hackett, Stephen Jan, John Lawson, Alexandra Martiniuk, Armin Mohammad, Ernie Somerville

\section{Operational Group}

Craig Anderson, Lucy Arblaster, Beverley Essue, Maree Hackett (C), Lorne Hyde, Stephen Jan, Lisa Todd

\section{Steering Committee}

Craig Anderson (C), Lucy Arblaster, Andrew Bleasel, Alastair Corbett, Nick Glozier, Gillian Gardner, Daniel Ghougassian, Deepak Gill, Maree Hackett, Bassel Hassan, Carol Ireland, Stephen Jan, John Lawson, Alexandra Martiniuk, Armin Mohammad, Maryanne Ng, Ernie Somerville, Lisa Todd

\section{Clinical Investigators}

Craig Anderson, Michael Barnett, Andrew Bleasel, Bruce Brew, Peter Brimage, Alastair Corbett, Lyndal Douglas, Daniel Ghougassin, Deepak Gill, Bassel Hassan, Natalie Hitchens, John Lawson, Joanne Leal, Armin Mohammad, Jenine Murray, Hyunmin Park, Hugo Alexandre Sampaio, David Sharpe, Ernie Somerville, Penny Spring, Con Yiannikas

$$
\begin{aligned}
& P I=\text { Principal investigator } \\
& C=\text { Chairperson }
\end{aligned}
$$

\section{Project managers}

Ms Lucy Arblaster (current), Ms Maryanne Ng (on leave), Mr Dan Jackson (previous), Ms Carol Burke (previous).

*Correct at the time of publication

\section{Acknowledgements}

This study is funded by a National Health and Medical Research Council (NHMRC) of Australia Partnership Grant 571448 and an Australian Research Council (ARC) Discovery Grant DP1096655. Funding partners include Epilepsy Action Australia, the Epilepsy Society of Australia, the Sydney South West Area Health Service New South Wales, and The George Institute for Global Health. During the completion of this work Craig Anderson was in receipt of a NHMRC Research Fellowship (2008-2012) grant, Maree Hackett was in receipt of a NHMRC Career Development Award 632925 (2010-2014) and Stephen Jan was in receipt of a NHMRC Career Development Award 457117 (2007-2011)

\section{Author details \\ 'Neurological and Mental Health Division, The George Institute for Global Health, The University of Sydney, Sydney, Australia. ${ }^{2}$ Psychological Medicine, The University of Sydney, Sydney, Australia. ${ }^{3}$ Injury Division, The George Institute for Gloabal Health, The University of Sydney, Sydney, Australia. ${ }^{4}$ Renal Division, The George Institute for Global Health, The University of Sydney, Sydney, Australia.}

\section{Authors' contributions}

CA is the principal investigator of SEISMIC and is responsible for the academic oversight of the study and the integrity of the data. $\mathrm{MH}$ drafted this manuscript which is based on the original SEISMIC study protocol drafted by NG, MH and AM. CA, NG, MH and AM jointly developed and 
wrote the protocol from its inception. SJ designed the economic analyses. AM designed the stigma component of the study. All authors were involved in revising the manuscript and gave final approval for publication.

\section{Competing interests}

The authors declare that they have no competing interests.

Received: 13 December 2010 Accepted: 9 January 2011

Published: 9 January 2011

\section{References}

1. Beran R, Hall L, Pesch A, Hoc P, Lamc S, Leungc P, Cheungc P, Fungc M: Population prevalence of Epilepsy in Sydney, Australia. Neuroepidemiology 1982, 1:201-208.

2. D'Souza WJ, Fryer JL, Quinn SJ, Taylor BV, Ficker DM, O'Brien TJ, Pearce NE, Cook MJ: The Tasmanian Epilepsy Register - A community-based cohort: background and methodology for patient recruitment from the Australian national prescription database. Neuroepidemiology 2007, 29:255-263.

3. Mathers C, Vos T, Stevenson C: The burden of disease and injury in Australia. AlHW cat no PHE 17 Canberra: AlHW; 1999

4. Leonardi M, Ustun TB: The global burden of epilepsy. Epilepsia 2002, 43(Suppl 6):21-25.

5. Kotsopoulos IA, van Merode T, Kessels FG, de Krom MC, Knottnerus JA: Systematic review and meta-analysis of incidence studies of epilepsy and unprovoked seizures. Epilepsia 2002, 43(11):1402-1409.

6. Forsgren L, Beghi E, Oun A, Sillanpa M: The epidemiology of epilepsy in Europe: a systematic review. European Journal of Neurology 2005, 12:245-253.

7. Benn EKT, Hauser WA, Shih T, Leary L, Bagiella E, Dayan P, Green R, Andrews $H$, Thurman DJ, Hesdorffer DC: Estimating the incidence of first unprovoked seizure and newly diagnosed epilepsy in the low-income urban community of Northern Manhattan, New York City. Epilepsia 2008, 49:1431-1439.

8. Heaney DC, MacDonald BK, Everitt A, Stevenson S, Leonardi GS, Wilkinson P, Sander JW: Socioeconomic variation in incidence of epilepsy: prospective community based study in south east England. BMJ 2002, 325:1013-1016.

9. Hesdorffer DC, Tian H, Anand K, Hauser WA, Ludvigsson P, Olafsson E, Kjartansson O: Socioeconomic status is a risk factor for epilepsy in Icelandic adults but not in children. Epilepsia 2005, 46:1297-1303.

10. Lhatoo SD, Sander WASS: Cause-specific mortality in epilepsy. Epilepsia 2005, 46:36-39.

11. Forsgren L, Hauser WA, Olafsson E, Sander JW, Sillanpaa M, Tomson T: Mortality of epilepsy in developed countries: a review. Epilepsia 2005, 46:18-27.

12. de Boer HM, Mula M, Sander JW: The global burden and stigma of epilepsy. Epilepsy \& Behaviour 2008, 12:540-546 [http://www.ncbi.nlm.nih. gov/pubmed/18280210 ]

13. Pellock JM: Understanding co-morbidities affecting children with epilepsy. Neurology 2004, 62:S17-S23.

14. Kwan P, Brodie MJ: Early identification of refractory epilepsy. New England Journal of Medicine 2000, 342:314-319.

15. Medical Research Council Antiepileptic Drug Withdrawal Study Group: A randomised study of antiepileptic drug withdrawal in patients in remission of epilepsy. Lancet 1991, 337(8751):1193-1194 [http://www.ncbi. nlm.nih.gov/pubmed/1673736 ]

16. Kwan P, Sander JW: The natural history of epilepsy: an epidemiological view. Journal of Neurology, Neurosurgery and Psychiatry 2004, 75:1376-1381.

17. Meyer A, Dua T, Ma J, Saxena S, Birbeck G: Global disparities in the epilepsy treatment gap: a systematic review. Bulletin of the World Health Organization 2010, 88:260-266.

18. Jacoby A, Snape D, Baker GA: Epilepsy and social identity: the stigma of a chronic neurological disorder. Lancet Neurology 2005, 4(3):171-178.

19. Wiebe S, Bellhouse DR, Fallahay C, Eliasziw M: Burden of epilepsy: the Ontario Health Survey. Canadian Journal of Neurological Sciences 1999, 26(4):263-270

20. McLaughlin DP, Pachana NA, Mcfarland K: Stigma, seizure frequency and quality of life: the impact of epilepsy in late adulthood. Seizure 2008, 17:281-287.
21. Johnson EK, Jones JE, Seidenberg M, Hermann BP: The relative impact of anxiety, depression, and clinical seizure features on health-related quality of life in epilepsy. Epilepsia 2004, 45(5):544-550.

22. Jacoby A, Baker GA, Steen N, Potts P, Chadwick DW: The clinical course of epilepsy and its psychosocial correlates: findings from a U.K. community study. Epilepsia 1996, 37(2):148-161.

23. Gaitatzis A, Trimble MR, Sander JW: The psychiatric comorbidity of epilepsy. Acta Neurologica Scandinavica 2004, 110(4):207-220.

24. Alanis-Guevara I, Peña E, Corona T, López-Ayala T, López-Meza E, LópezGómez M: Sleep disturbances, socioeconomic status, and seizure control as main predictors of quality of life in epilepsy. Epilepsy \& Behaviour 2005, 7(3):481-485 [http://www.ncbi.nlm.nih.gov/pubmed/16098815]

25. Christensen J, Vestergaard M, Mortensen PB, Sidenius P, Agerbo E: Epilepsy and risk of suicide: a population-based case-control study. The Lancet Neurology 2007, 6(8):693-698

26. Tellez-Zenteno JF, Patten SB, Jetté N, Williams J, Wiebe S: Psychiatric comorbidity in epilepsy: a population-based analysis. Epilepsia 2007. 48(12):2336-2344.

27. Rodenburg R, Stams GJ, Meijer AM, Aldenkamp AP, Deković M: Psychopathology in Children with Epilepsy: A Meta-Analysis. Journal of Pediatric Psychology 2005, 30(6):453-468.

28. Kwan $P, Y u E$, Leung $H$, Leon T, Mychaskiw MA: Association of subjective anxiety, depression, and sleep disturbance with quality-of-life ratings in adults with epilepsy. Epilepsia 2009, 50(5):1059-1066

29. Strine TW, Kobau R, Chapman DP, Thurman DJ, Price P, Balluz LS: Psychological Distress, Comorbidities, and Health Behaviors among U.S Adults with Seizures: Results from the 2002 National Health Interview Survey. Epilepsia 2005, 46(7):1133-1139.

30. Zeber JE, Copeland LA, Amuan M, Cramer JA, Pugh MJ: The role of comorbid psychiatric conditions in health status in epilepsy. Epilepsy and Behaviour 2007, 10(4):539-546.

31. Thompson AW, Miller JW, Katon W, Chaytor N, Ciechanowski P. Sociodemographic and clinical factors associated with depression in epilepsy. Epilepsy and Behaviour 2009, 14(4):655-660

32. Loring DW, Meador KJ, Lee GP: Determinants of quality of life in epilepsy. Epilepsy \& Behaviour 2004, 5(6):976-980 [http://www.ncbi.nlm.nih.gov/ pubmed/15582847 ]

33. Hermann B, Seidenberg M, Sager M, Carlsson C, Gidal B, Sheth R, Rutecki P, Asthana S: Growing old with epilepsy: the neglected issue of cognitive and brain health in aging and elder persons with chronic epilepsy. Epilepsia 2008, 49(5):731-740

34. Reisinger EL, Dilorioa C: Individual, seizure-related, and psychosocial predictors of depressive symptoms among people with epilepsy over six months. Epilepsy \& Behavior 2009, 15(2):196-201 [http://www.ncbi.nlm.nih. gov/pubmed/19303457 ]

35. Taylor J, Jacoby A, Baker GA, Marson AG, Ring A, Whitehead M: Factors predictive of resilience and vulnerability in new-onset epilepsy. Epilepsia 2010, 1-9 [http://www.ncbi.nlm.nih.gov/pubmed/21070216 ], Article first published online: 10 NOV 2010

36. Amir M, Roziner I, Knoll A, Neufeld MY: Self-efficacy and social support as mediators in the relation between disease severity and quality of life in patients with epilepsy. Epilepsia 1999, 40(2):216-224.

37. Beran R, Pachlatko C: Final Report of the ILAE Commission on Economic Aspects of Epilepsy, 1994-1997. Epilepsia 1997, 38(12):1359-1362.

38. Begley CE, Baker GA, Beghi E, Butler J, Chisholm D, Langfitt JT, Levy P, Pachlatko C, Wiebe S, Donaldson KL, et al: Cross-country measures for monitoring epilepsy care. Epilepsia 2007, 48(5):990-1001.

39. Cockerell OC, Hart YM, Sander JW, Shorvon SD: The cost of epilepsy in the United Kingdom: an estimation based on the results of two populationbased studies. Epilepsy Research 1994, 18(3):249-260

40. Beran R, Read T: A survey of doctors in Sydney, Australia: perspectives and practices regarding epilepsy and those affected by it. Epilepsia 1983, 24(1):79-104

41. Beran R, Hall L, Michelazzi J: An accurate assessment of the prevalence ratio of epilepsy adequately adjusted by influencing factors. Neuroepidemiology 1985, 4(2):71-81.

42. Opeskin K, Cordner SM, Berkovic SF, Harvey AS: Sudden unexpected death in epilepsy in Victoria. Journal of Clinical Neuroscience 2000, 7(1):34-37.

43. Opeskin K, Berkovic SF: Risk factors for sudden unexpected death in epilepsy: a controlled prospective study based on coroners cases. Seizure 2003, 12(7):456-464. 
44. Lacey CJ, Salzberg MR, Roberts H, Trauer T, D'Souza WJ: Psychiatric comorbidity and impact on health service utilization in a community sample of patients with epilepsy. Epilepsia 2009, 50(8):1991-1994.

45. Bladin PF: Psychosocial Difficulties and Outcome After Temporal Lobectomy. Epilepsia 1992, 33:898-907.

46. Stavem K, Bjørnaes H, Lossius MI: Properties of the 15 D and EQ-5 D utility measures in a community sample of people with epilepsy. Epilepsy Research 2001, 44:179-189.

47. The EuroQol Group: EuroQol - a new facility for the measurement of health related quality of life. Health Policy 1990, 16:199-208.

48. Broadbent E, Petrie KJ, Main J, Weinman J: The brief illness perception questionnaire. J Psychosomat Res 2006, 60:631-637.

49. Üstün TB, Chatterji S, Kostanjsek N, Rehm J, Kennedy C, Epping-Jordan J, Saxena S, von Korff M, Pull C, in collaboration with WHO/NIH Joint Project Collaborators: Developing the World Health Organization Disability Assessment Schedule 2.0. Bulletin of the World Health Organization 2010, 88(11):815-823.

50. Goodman R, Ford T, Simmons H, Gatward R, Meltzer H: Using the Strengths and Difficulties Questionnaire (SDQ) to screen for child psychiatric disorders in a community sample. British Journal of Psychiatry 2000, 177:534-539.

51. Bush K, Kivlahan DR, McDonell MB, Fihn SD, Bradley KA, for the Ambulatory Care Quality Improvement Project (ACOUIP): The AUDIT Alcohol Consumption Questions (AUDIT-C): an effective brief screening test for problem drinking. Archives of Internal Medicine 1998, 158:1789-1795.

52. Trewin D: How Australia takes a census Canberra: Australian Bureau of Statistics; 2006

53. Karasek R, Brisson C, Kawakami N, Houtman I, Bongers P, Amick B: The Job Content Questionnaire (JCQ): an instrument for internationally comparative assessments of psychosocial job characteristics. Journal of Occupational Health Psychology 1998, 3:322-355.

54. Baumann K: Direct measures of poverty as indicators of economic need: evidence from the Survey of Income and Program participation. Population Division Technical Working Paper No 30 Washington DC: US Census; 1998 [http://www.census.gov/population/www/documentation/ twps0030/twps0030.html ].

55. Good MJ, Smilkstein G, Good BJ, Shaffer T, Arrons T: The family APGAR index: a study of construct validity. J Fam Pract 1979, 8:577-582.

56. Gardner DL, Huber $\mathrm{CH}$, Steiner R, Vazquez LA, Savage TA: The Development and Validation of the Inventory of Family Protective Factors: A Brief Assessment for Family Counseling. The Family Journal 2008, 16:107-117.

57. Zigmond AS, Snaith RP: The Hospital Anxiety and Depression Scale. Acto Psychiatrica Scandinavica 1983, 67:361-370.

58. Goldberg DP, Williams P: A user's guide to the General Health Questionnaire Windsor: NFER-Nelson; 1988.

59. Berger BE, Ferrans CE, Lashley FR: Measuring stigma in people with HIV: psychometric assessment of the HIV stigma scale. Research Nursing and Health 2001, 24(6):518-529.

60. Buysse DJ, Reynolds CF, Monk TH, Berman SR, Kupfer DJ: The Pittsburgh Sleep Quality Index: a new instrument for psychiatric practice and research. Psychiatry Research 1989, 28(2):193-213.

61. Cramer JA, Westbrook LE, Devinsky O, Perrine K, Glassman MB, Camfield C Development of the Quality of Life in Epilepsy Inventory for Adolescents: The QOLIE-AD-48. Epilepsia 1999, 40:1114-1121.

62. Gray M, Smart D: Growing Up in Australia: The Longitudinal Study of Australian Children Is Now Walking and Talking. Family Matters 2008, 79:5-13[http://www.aifs.gov.au/institute/pubs/fm2008/fm79.html ].

63. de Jager CA, Budge MM, Clarke R: Utility of TICS-M for the assessment of cognitive function in older adults. International Journal of Geriatric Psychiatry 2003, 18:318-324.

64. Berg AT, Berkovic SF, Brodie MJ, Buchhalter J, Cross JH, Van Emde Boas W, Engel J, French J, Glauser TA, Mathern GW, et al: Revised terminology and concepts for organization of seizures and epilepsies: Report of the ILAE Commission on Classification and Terminology, 2005-2009. Epilepsia 2010, 51(4):676-685

65. Broadhead WE, Blazer DG, George LK, Tse CK: Depression, disability days, and days lost from work in a prospective epidemiologic survey. JAMA 1990, 264(19):2524-2528

66. Salvi F, Miller MD, Grilli A, Giorgi R, Towers AL, Morichi V, Spazzafumo L, Mancinelli L, Espinosa E, Rappelli A, et al: A manual of guidelines to score the modified cumulative illness rating scale and its validation in acute hospitalized elderly patients. Journal of the American Geriatric Society 2008, 56(10):1936-1921.

67. Rehm J, Üstün TB, Saxena S, Nelson CB, Chatterji S, Ivis F, Adlaf E: On the development and psychometric testing of the $\mathrm{WHO}$ screening instrument to assess disablement in the general population. International Journal of Methods in Psychiatric Research 1999, 8:110-122.

\section{Pre-publication history}

The pre-publication history for this paper can be accessed here: http://www.biomedcentral.com/1471-2377/11/3/prepub

doi:10.1186/1471-2377-11-3

Cite this article as: Hackett et al:: Sydney epilepsy incidence study to measure illness consequences: the SESIMIC observational epilepsy study protocol. BMC Neurology 2011 11:3

\section{Submit your next manuscript to BioMed Central and take full advantage of:}

- Convenient online submission

- Thorough peer review

- No space constraints or color figure charges

- Immediate publication on acceptance

- Inclusion in PubMed, CAS, Scopus and Google Scholar

- Research which is freely available for redistribution

Submit your manuscript at www.biomedcentral.com/submit 